\title{
Faktor Penyebab Kegagalan Akibat Keterlambatan Proyek Konstruksi Pada Bangunan Gedung di Kota Padang
}

\author{
Riswandi, Monika Natalia, Mafriyal, Gusri Yaldi, Therisia Cristiani \\ Jurusan Teknik Sipil, Politeknik Negeri Padang \\ Email : riswandi@pnp.ac.id,monikanatalia75@gmail.com, mafriyal@gmail.com, \\ gusri.yaldi@gmail.com, Therisiacristiani11@gmail.com
}

\begin{abstract}
Abstrak-Keberhasilan proyek adalah tujuan akhir yang utama dari setiap pelaksanaan proyek konstruksi gedung. Perbedaan keberhasilan proyek disebabkan karena tiap proyek mempunyai faktor-faktor pengaruh yang berbeda-beda. Ada kalanya proyek tidak berjalan lancar sesuai perencanaan awal. Hal ini disebabkan oleh banyak faktor, seperti faktor alam, faktor tenaga kerja, lokasi, material, koordinasi, administrasi dan lain-lain. Faktor-faktor tersebut dapat menjadi permasalahan atau kendala yang menyebabkan tidak lancarnya pelaksanaan proyek konstruksi. Padahal proyek konstruksi harus memenuhi tiga criteria yaitu mutu, biaya, dan waktu (triple constraint) sesuai dengan yang telah ditetapkan.Oleh karena itu, semua pihak yang terlibat dalam proyek konstruksi gedung (owner, konsultan, kontraktor) harus mengetahui faktor-faktor penyebab kendala selama pelaksanaan proyek konstruksi gedung. Dengan diketahuinya faktor-faktor ini, semua pihak yang terlibat dapat menentukan solusi/strategi apa yang harus dilakukan untuk menangani masalah yang timbul di lapangan selama pelaksanaan proyek konstruksi. Dengan diketahui dari awal, dapat diantisipasi sedini mungkin semua kendala/permasalahan yang timbul, dan tidak akan ada pihak yang dirugikan.Penelitian ini bertujuan untuk mengidentifikasi faktor-faktor penyebab kendala kegagalan yang disebabkan oleh keterlambatan pelaksanaan proyek konstruksi di Kota Padang Sumatera Barat. Metode Penelitian yang digunakan analisis deskriptif menggunakan quisioner dengan data proyek konstruksi yang sedang atau sudah dikerjakan di Sumatera Barat. Adapun respondennya adalah project manager, site manager.Dari quisioner yang dilakukan pengujian data dengan menggunakan SPSS. Pengujian data meliputi uji validasi, uji reliabilitas,uji normalitas uji korelasi,dan uji analisa diskritif. Adapun tujuan dari penelitian ini adalah untuk mengetahui faktor dominan penyebab kendala proyek konstruksi di Kota Padang adapun faktor dominan pada pengujian ini yaitu pada subfaktor jadwal penggunaan material yang terperinci dan tepat waktu (material's schedule) dengan nilai mean 3,55 atau 87,50 \% . Hasil penelitian ini nantinya diharapkan dapat sebagai bahan masukan/pertimbangan dalam mengambil kebijakan untuk semua pihak yang terlibat dalam pelaksanaan proyek konstruksi agar tercapai keberhasilan proyek
\end{abstract}

Kata kunci: Kegagalan Akibat kendala keterlambatan (schedule)

\section{PENDAHULUAN}

\subsection{Latar Belakang}

Proyek konstruksi mempunyai sasaran (target) tertentu dengan batasan-batasan mutu pekerjaan (performance), anggaran (cost), dan jadwal (time), yang dikenal sebagai Triple Constraint. Proyek harus diselesaikan dengan biaya yang tidak melebihi anggaran, Proyek harus dikerjakan sesuai dengan kurun waktu yang telah ditentukan. Penyerahan proyek tidak boleh melewati batas waktu yang telah ditentukan. Produk akhir proyek harus memenuhi spesifikasi dan kriteria yang dipersyaratkan. Sebagai contoh, bila hasil kegiatan proyek tersebut berupa sebuah bangunan pabrik, maka pabrik tersebut harus memenuhi kriteria : mampu beroperasi secara memuaskan dalam jangka waktu yang telah ditentukan. Memenuhi persyaratan mutu berarti mampu memenuhi tugas yang dimaksudkan (fit for the intended use). 
Keberhasilan sasaran proyek adalah tujuan akhir yang utama dari setiap pelaksanaan proyek konstruksi. Perbeda- an keberhasilan proyek disebabkan karena tiap proyek mempunyai faktor-faktor pengaruh yang berbeda-beda.. Hal ini disebabkan oleh banyak faktor, seperti faktor alam, faktor tenaga kerja, waktu, lokasi, material, koordinasi, administrasi, manajerial, kecelakaan kerja dan lain-lain. Faktor kecelakaan kerja seperti yang baru-baru ini terjadi yaitu ambruknya alat berat crane di proyek pembangunan jalur kereta di Matraman Jakarta Pusat, kecelakaan pada proyek pembangunan jalan tol DepokAntasari,runtuhnya atap Manhattan Mall dan Kondominium di Medan. Hal ini dikarenakan kegagalan manajemen konstruksi, bukan sekedar kegagalan teknis. Kejadian-kejadian tersebut merupakan contoh indikator penyebab kendala/ permasalahan yang butuh penanganan yang tepat agar sasaran proyek tetap terpenuhi.

Dipohusodo (1995), upaya untuk melakukan pengendalian triple constraint merupakan proses pengukuran ,evaluasi dan membetulkan kinerja proyek. Untuk proyek konstruksi unsur yang perlu selalu dikendalikan dan diukur yaitu kemajuan (progress) yang dicapai dibandingkan terhadap kesepakatan kontrak, pembiayaan terhadap rencana anggaran dan mutu hasil pekerjaan terhadap spesifikasi teknis. Menurut Ermis (2010), waktu dan biaya sangat berpengaruh terhadap keberhasilan dan kegagalan suatu proyek. Tolak ukur dari keberhasilan proyek biasanya dilihat dari waktu penyelesaian yang singkat dengan biaya yang minimal tanpa meninggalkan mutu hasil pekerjaan. Oleh karena itu, usaha untuk mengoptimalkan waktu dan biaya sangat penting dalam perencanaan suatu proyek. Pengelolaan proyek secara sistematis diperlukan untuk memastikan waktu pelaksanaanproyek sesuai dengan kontrak atau bahkan lebih cepat sehingga biaya yang dikeluarkan bisa memberikan keuntungan. Selain itu, menghindarkan dari adanya denda akibat keterlambatan penyelesaian proyek.

Untuk mengantisipasi kendala (permasa- lahan-permasalahan) triple constraint supaya tidak ada penyimpangan dalam progres/waktu pelaksanaan perlu diketahui terlebih dulu faktor-faktor penyebabnya. Dengan mengetahui faktor penyebab kendala pelaksanaan proyek konstruksi, dapat dilakukan sedini mungkin pengendalian triple constraint sehingga dapat meminimalis kemungkinan kerugian dan dapat memaksimalkan keuntungan yang didapat dengan tidak mengurangi mutu (kualitas) pekerjaan.

Penelitian ini sangat dibutuhkan untuk mengantisipasi kendala-kendala kegagalan akibat keterlambatn tersebut agar tidak menjadi masalah di kemudian hari bagi semua pihak yang terlibat dalam proyek konstruksi (owner, konsultan, kontraktor) perlu mengetahui apa saja faktor-faktor penyebab terjadinya kendala tersebut. Dengan diketahui faktor-faktor penyebab terjadinya kendala selama pelaksanaan proyek konstruksi, semua pihak yang terlibat dalam mengambil kebijakan dan keputusan yang tepat dalam solusi permasalahannya sehingga dapat dicapai keberhasilan proyek sesuai dengan sasaran yang telah ditetapkan. 


\subsection{Rumusan Masalah}

1. Faktor apakah yang paling dominan menjadi penyebab kegagalan akibat keterlambatan proyek konstruksi pada bangunan gedung dikota padang .

2. Bagaimana pengaruh dari faktor penyebab kegagalan akibat keterlamba- tan proyek konstruksi pada bangunan gedung dikota padang.

\subsection{Batasan Masalah}

1. Penelitian dilakukan pada proyek yang mengalami kegagalan akibat keterlambatan pelaksanaan proyek konstruksi gedung yang berada di wilayah Sumatera Barat khususnya kota Padang yang terdaftar sebagai anggota GAPENSI kota Padang.

2. Metode pengumpulan data dengan cara penyebaran kuisioner.

3. Penyebaran kuisioner dilakukan kepada project manager, site manager yang sudah selesai atau sedang mengerjakan proyek konstruksi gedung di kota Padang dalam kurun waktu 10 (sepuluh) tahun terakhir sampai sekarang dengan kualifikasi kontraktornya yaitu M1-M2 dengan nilai proyek $>2 \mathrm{M}$.

4. Pengisian kuesioner diisi oleh staf kont-raktor yang telah memiliki pengalaman di bidang konstruksi gedung.

5. Analisis data menggunakan program SPSS VERSI 23.00

\subsection{Tujuan Penelitian}

1. Untuk mengetahui faktor penyebab kegagalan yang disebabkan oleh keterlambatan penyelesaian proyek konstruksi gedung di kota padang.

2. Untuk mengetahui bagaimana hubungan antara faktor penyebab keterlambatan penyelesaian proyek konstruksi gedung terhadap biaya.

\subsection{Proyek Konstruksi}

Dipohusodo (1995), proyek merupakan suatu upaya yang mengerahkan sumber daya yang tersedia, yang diorganisasikan untuk mencapai tujuan, sasaran dan harapan penting tertentu serta harus diselesaikan dalam jangka waktu tertentu sesuai dengan kesepakatan.

\subsection{Manajemen Konstruksi}

Dipohusodo (1996), Manajemen merupakan proses terpadu dimana individuindividu sebagai bagian dari organisasi dilakukan untuk memelihara, mengembang kan, mengendalikan, dan menjalankan program, yang semuanya diarahkan pada sasaran yang telah ditetapkan dan berjalan terus menerus seiring dengan berjalannya waktu.

\subsection{Pengertian Triple Constraint}

Dalam proses mencapai tujuan ada batasan yang harus dipenuhi yaitu besar biaya (anggaran) yang dialokasikan, jadwal, serta mutu yang harus dipenuhi. Ketiga hal tersebut merupakan parameter penting bagi penyelenggara proyek yang sering diasosiasikan sebagai sasaran proyek.

\subsection{Faktor-faktor penyebab Keterlambatan}

1. Faktor yang disebabkan oleh kontraktor

- Keterlambatan pengiriman material ke lokasi proyek 
- Kekurangan material di lapangan

- Kesalahan dan cacat dalam

2. Faktor yang disebabkan oleh konsultan

- Kurangnya tenaga ahli professional

- Kurangnya pengalaman konsultan

- Dokumen yang tidak lengkap

3. Faktor yang disebkan oleh owner

- Belum menguasai bidang pekerjaan

- Lambat dalam membuat keputusan

- Masalah keuangan

\subsection{Dampak-Dampak Kendala proyek}

Obrien JJ, 1976 (dalam Suyatno, 2010), menyimpulkan bahwa dampak keterlamba-tan menimbulkan kerugian:

1. Bagi pemilik, keterlambatan menyebabkan kehilangan penghasilan dari bangunan yang seharusnya sudah bisa digunakan atau disewakan.

2. Bagi kontraktor, keterlambatan penyelesaian proyek berarti naiknya overhead kerena bertambah panjang waktu pelaksanaan sehingga merugikan akibat kemungkinan naiknya harga karena inflasi dan naiknya upah buruh, juga akan tertahannya modal kontraktor yang kemungkinan besar dapat dipakai untuk proyek lain.

3. Bagi konsultan, keterlambatan akan mengalami kerugian waktu, karena dengan adanya keterlambatan tersebut konsultan yang bersangkutan akan terhambat dalam mengagendakan proyek lainnya.

\subsection{Pertanggungjawaban kendala}

\section{Keterlambatan (Delay Responsibility)}

Menurut Ahmed (2003) pihak-pihak yang bertanggungjawab dalam keterlamb-atan proyek dikategorikan menjadi:

1. Tanggung jawab owner (pemilik) : kontraktor berhak atas tambahan waktu dan biaya

2. Tanggungjawab kontraktor dan subkontraktor: kontraktor harus melakukan perbaikan atas kegagalan fisik bangunan atas kinerjanya dan bisa mendapat penalti.

3. Pihak lain (Act of God): kontraktor akan mendapatkan tambahan waktu untuk menyelesaikan proyek tetapi tidak untuk biaya. Serta kegagalan fisik yang disebabkan oleh "act of God" tidak menyebabkan pinalti bagi kontraktor.

\subsection{Komponen Biaya Konstruksi}

\subsubsection{Komponen Biaya Langsung Konstruksi}

Biaya langsung adalah semua biaya yang menjadi komponen permanen hasil akhir proyek, terdiri dari biaya material, biaya peralatan, biaya upah tenaga kerja dan biaya subkontraktor (Oberlender dan Peurifoy, 2002)

\subsubsection{Komponen Biaya Tidak}

\section{Langsung Konstruksi}

Menurut Oberlender dan Peurifoy (2002) biaya tidak langsung adalah semua biaya yang mendukung pekerjaan tetapi tidak tercantum dalam mata pembayaran seperti biaya overhead (general overhead dan 
project overhead), contingencies dan

keuntungan (profit).

\section{METODE PENELITIAN}

\subsection{Diagram Alir}

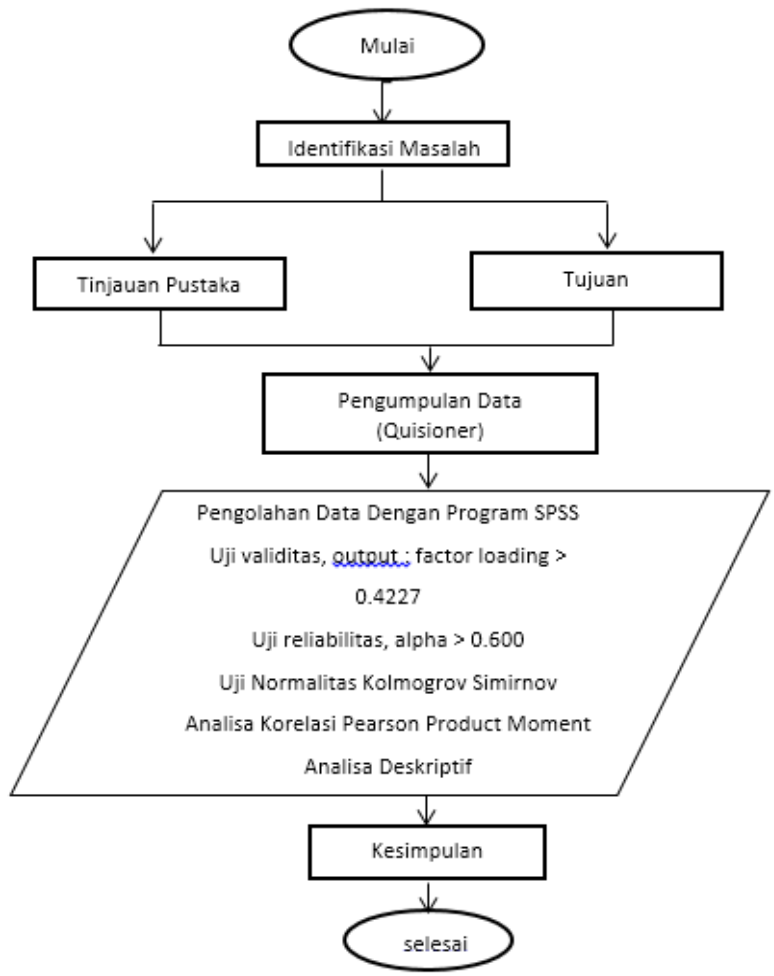

Variable:

\begin{tabular}{|c|c|c|c|}
\hline No & $\begin{array}{c}\text { Variab } \\
\text { el }\end{array}$ & Indikator Pernyataan & $\begin{array}{c}\text { Variabl } \\
\text { e } \\
\text { Bebas }\end{array}$ \\
\hline \multicolumn{4}{|c|}{ Variabel X1: } \\
\hline \multirow[t]{4}{*}{1} & \multirow[t]{4}{*}{$\begin{array}{c}\text { Bahan } \\
\text { (Materi } \\
\text { al) }\end{array}$} & $\begin{array}{l}\text { Kualitas bahan serta } \\
\text { pengontrolan mutu } \\
\text { material dilapangan } \\
\text { dan laboratorium } \\
\text { sesuai spesifikasi } \\
\text { teknis }\end{array}$ & $\mathrm{X} 1,1$ \\
\hline & & $\begin{array}{l}\text { Persetujuan bahan } \\
\text { yang ditetapkan dan } \\
\text { direncanakan lebih } \\
\text { terperinci }\end{array}$ & $\mathrm{X} 1,2$ \\
\hline & & $\begin{array}{l}\text { Proses pengiriman } \\
\text { bahan dari lokasi } \\
\text { pembelian ke lokasi } \\
\text { proyek }\end{array}$ & $\mathrm{X} 1,3$ \\
\hline & & $\begin{array}{l}\text { Ketersediaan ruang } \\
\text { untuk penempatan } \\
\text { material dilokasi } \\
\text { proyek beserta } \\
\text { pengontrolan mutu }\end{array}$ & $X 1,4$ \\
\hline
\end{tabular}

\begin{tabular}{|c|c|c|c|}
\hline & & $\begin{array}{l}\text { material di tempat } \\
\text { penyimpanan }\end{array}$ & \\
\hline & & $\begin{array}{l}\text { Kerusakan material di } \\
\text { gudang (tempat } \\
\text { material) }\end{array}$ & $X 1,5$ \\
\hline & & $\begin{array}{l}\text { Gambar detail yang } \\
\text { kurang lengkap }\end{array}$ & $\mathrm{X} 1,6$ \\
\hline & & $\begin{array}{l}\text { Sistem administrasi } \\
\text { bahan yang } \\
\text { terencana dan } \\
\text { terperinci }\end{array}$ & $X 1,7$ \\
\hline & & $\begin{array}{l}\text { Karakteristik bahan } \\
\text { dan spesifikasi teknis }\end{array}$ & $\mathrm{X} 1,8$ \\
\hline & & $\begin{array}{l}\text { Fasilitas infrastruktur } \\
\text { pendukung disekitar } \\
\text { lokasi proyek }\end{array}$ & $X 1,9$ \\
\hline & & $\begin{array}{l}\text { Ketersediaan } \\
\text { kuantitas material } \\
\text { pada proses } \\
\text { pelaksanaan } \\
\text { pekerjaan }\end{array}$ & $\mathrm{X} 1,10$ \\
\hline & & $\begin{array}{l}\text { Jadwal penggunaan } \\
\text { material yang } \\
\text { terperinci dan tepat } \\
\text { waktu (material's } \\
\text { schedule) }\end{array}$ & $\mathrm{X} 1,11$ \\
\hline & & $\begin{array}{l}\text { Harga bahan yang } \\
\text { naik sewaktu-waktu }\end{array}$ & $\mathrm{X} 1,12$ \\
\hline & bel X2 & & \\
\hline 2 & $\begin{array}{c}\text { Tenag } \\
a \\
\text { Kerja }\end{array}$ & $\begin{array}{l}\text { Kekurangan tenaga } \\
\text { kerja }\end{array}$ & $\mathrm{X} 2,1$ \\
\hline & $\begin{array}{l}\text { (man } \\
\text { power }\end{array}$ & $\begin{array}{l}\text { Kemampuan tenaga } \\
\text { kerja }\end{array}$ & $X 2,2$ \\
\hline & ) & $\begin{array}{l}\text { Kesukuan atau } \\
\text { nasionalisme dan } \\
\text { kultur tenaga kerja }\end{array}$ & $\mathrm{X} 2,3$ \\
\hline & & $\begin{array}{l}\text { Tempat tinggal } \\
\text { tenaga kerja selama } \\
\text { pelaksanaan proyek }\end{array}$ & X2.4 \\
\hline & & $\begin{array}{l}\text { Informasi ruang } \\
\text { lingkup pembagian } \\
\text { kerja yang tidak detail } \\
\text { dan terencana }\end{array}$ & X2.5 \\
\hline & & $\begin{array}{l}\text { Pengaturan jadwal } \\
\text { tenaga kerja }\end{array}$ & X2.6 \\
\hline & & $\begin{array}{l}\text { Kurangnya } \\
\text { produktifitas tenaga } \\
\text { kerja }\end{array}$ & X2.7 \\
\hline & & $\begin{array}{l}\text { Keahlian berdasarkan } \\
\text { pengalaman tenaga } \\
\text { kerja }\end{array}$ & $\mathrm{X} 2.8$ \\
\hline
\end{tabular}




\begin{tabular}{|c|c|c|c|}
\hline \multirow[t]{12}{*}{3} & \multirow{12}{*}{$\begin{array}{c}\text { Faktor } \\
\text { Peralatan } \\
\text { (equipment) }\end{array}$} & $\begin{array}{l}\text { Kerusakan } \\
\text { peralatan }\end{array}$ & X3.1 \\
\hline & & $\begin{array}{l}\text { Kekurangan } \\
\text { peralatan }\end{array}$ & X3.2 \\
\hline & & $\begin{array}{l}\text { Keterlambatan } \\
\text { pengiriman } \\
\text { peralatan }\end{array}$ & X3.3 \\
\hline & & $\begin{array}{l}\text { Keahlian } \\
\text { mandor dan } \\
\text { operator } \\
\text { kurang }\end{array}$ & X3.4 \\
\hline & & $\begin{array}{l}\text { Produktifitas } \\
\text { peralatan }\end{array}$ & X3.5 \\
\hline & & $\begin{array}{l}\text { Kesalahan } \\
\text { manajemen } \\
\text { peralatan }\end{array}$ & X3.6 \\
\hline & & $\begin{array}{l}\text { Ketersediaan } \\
\text { dan kondisi } \\
\text { peralatan pada } \\
\text { saat } \\
\text { pelaksanaan } \\
\text { pekerjaan }\end{array}$ & X3.7 \\
\hline & & $\begin{array}{l}\text { Kerusakan } \\
\text { peralatan pada } \\
\text { saat } \\
\text { pelaksanaan } \\
\text { pekerjaan }\end{array}$ & X3.8 \\
\hline & & $\begin{array}{l}\text { Pemeliharaan } \\
\text { peralatan dan } \\
\text { ketersediaan } \\
\text { bahan bakar }\end{array}$ & X3.9 \\
\hline & & $\begin{array}{l}\text { Metoda kerja } \\
\text { berdasarkan } \\
\text { jenis peralatan }\end{array}$ & X3.10 \\
\hline & & $\begin{array}{l}\text { Ruang untuk } \\
\text { penempatan } \\
\text { peralatan di } \\
\text { lokasi proyek }\end{array}$ & X3.11 \\
\hline & & $\begin{array}{l}\text { Kemampuan } \\
\text { operator dari } \\
\text { masing-masing } \\
\text { peralatan }\end{array}$ & X3.12 \\
\hline \multicolumn{4}{|c|}{ Variabel X4 : } \\
\hline \multirow[t]{4}{*}{4} & \multirow[t]{4}{*}{$\begin{array}{l}\text { Keuangan } \\
\text { (financing) }\end{array}$} & $\begin{array}{l}\text { Ketersediaan } \\
\text { keuangan } \\
\text { selama } \\
\text { Pelaksanaan }\end{array}$ & X4.1 \\
\hline & & $\begin{array}{l}\text { Keterlambatan } \\
\text { proses } \\
\text { pembayaran } \\
\text { oleh } \\
\text { Owner }\end{array}$ & $X 4.2$ \\
\hline & & $\begin{array}{l}\text { Situasi } \\
\text { perekonomian } \\
\text { nasional }\end{array}$ & X4.3 \\
\hline & & $\begin{array}{l}\text { Fluktuasi nilai } \\
\text { rupiah terhadap } \\
\text { dolar }\end{array}$ & $X 4.4$ \\
\hline
\end{tabular}

\begin{tabular}{|c|c|c|c|}
\hline \multicolumn{4}{|c|}{ Variabel X5 : } \\
\hline \multirow[t]{5}{*}{5} & \multirow{5}{*}{$\begin{array}{c}\text { Lingkungan } \\
\text { (environment } \\
\text { ) }\end{array}$} & $\begin{array}{l}\text { Faktor sosial } \\
\text { dan budaya }\end{array}$ & $\times 5.1$ \\
\hline & & Premanisme & X5.2 \\
\hline & & $\begin{array}{l}\text { Akses ke lokasi } \\
\text { proyek sulit }\end{array}$ & X5.3 \\
\hline & & $\begin{array}{l}\text { Pengaruh } \\
\text { udara panas } \\
\text { pada saat } \\
\text { pelaksanaan } \\
\text { konstruksi }\end{array}$ & $X 5.4$ \\
\hline & & $\begin{array}{l}\text { Pengaruh } \\
\text { udara dingin } \\
\text { pada saat } \\
\text { pelaksaan } \\
\text { konstruksi }\end{array}$ & $\times 5.5$ \\
\hline \multicolumn{4}{|c|}{ Variabel X6 : } \\
\hline \multirow[t]{4}{*}{6} & \multirow[t]{4}{*}{$\begin{array}{c}\text { Perubahan } \\
\text { (change) }\end{array}$} & $\begin{array}{l}\text { Terjadi } \\
\text { perubahan } \\
\text { desain oleh } \\
\text { Owner }\end{array}$ & X6.1 \\
\hline & & $\begin{array}{l}\text { Seringnya } \\
\text { terjadi } \\
\text { pekerjaan } \\
\text { tambah }\end{array}$ & X6.2 \\
\hline & & $\begin{array}{l}\text { Perubahan } \\
\text { ling- kup } \\
\text { pekerjaan pada } \\
\text { waktu } \\
\text { pelaksanaan }\end{array}$ & X6.3 \\
\hline & & $\begin{array}{l}\text { Kesalahan } \\
\text { desain yang } \\
\text { dibuat oleh } \\
\text { Perencana }\end{array}$ & X6.4 \\
\hline \multicolumn{4}{|c|}{ Variabel X7: } \\
\hline \multirow[t]{4}{*}{7} & \multirow[t]{4}{*}{$\begin{array}{c}\text { Kontrak } \\
\text { (contraktual } \\
\text { relationship) }\end{array}$} & $\begin{array}{l}\text { Konflik antara } \\
\text { kontraktor dan } \\
\text { Konsultan }\end{array}$ & X7.1 \\
\hline & & $\begin{array}{l}\text { Kurangya } \\
\text { koordinasi } \\
\text { antara } \\
\text { kontraktor } \\
\text { dengan owner }\end{array}$ & $X 7.2$ \\
\hline & & $\begin{array}{l}\text { Keterlambatan } \\
\text { owner dalam } \\
\text { pengambilan } \\
\text { keputusan }\end{array}$ & X7.3 \\
\hline & & $\begin{array}{l}\text { Negosiasi dan } \\
\text { perijinan dalam } \\
\text { kontrak }\end{array}$ & X7.4 \\
\hline
\end{tabular}




\section{Uji Validitas}

Uji validitas dilakukan guna menentukan seberapa valid suatu item pertanyaan mengukur variable yang diteliti. Agar penelitian ini lebih teliti, sebuah item sebaiknya memiliki korelasi ( $r$ ) dengan skor total masing-masing variable. Dengan kriteria pengujian : Jika $r$ hitung $\geq r$ tabel maka angket dikatakan valid. Jika $r$ hitung $\geq r$ tabel yaitu 0,4227 (junaidi (http:// junaidichaniago.wordpress.com) maka angket dikatakan valid. Jika $r$ hitung $<r$ tabel $(0,4227)$ maka angket dikatakan tidak valid.

Jika $r_{o} \geq r_{t a b}$ dinyatakan valid atau jika $r_{\circ} \geq 0,4227$ dinyatakan valid

Jika $r_{o}<r_{\text {tab }}$ dinyatakan tidak valid jika $r_{o}<0,4227$ dinyatakan tidak valid

\section{Uji Reliabilitas}

Uji reliabilitas digunakan guna menentukan reliabilitas serangkaian item pertanyaan dalam kehandalannnya mengukur variable. Uji reliabilitas dilakukan dengan bantuan program SPSS versi 23.00 yaitu dengan melihat nilai kefisien cronbach alpha.

Kriteria pengujian ini adalah jika nilai koefisien cronbach alpha $(\mathrm{r} 11)>0.90$ maka reliabilitas sempurna. Jika nilai koefisien cronbach alpha antara 0.70-0.90 maka reliabilitas dikatakan tinggi. Jika nilai koefisien cronbach alpha antara 0.50-0.70 maka reliabilitas moderat/sedang. Jika alpha $<0.50$ mka reliabilitas rendah.

\section{Uji Normalitas Kolmogorov Smirnov}

Uji distribusi normal adalah uji untuk mengukur apakah data kita memiliki distribusi normal sehingga dapat dipakai dalam statistik parametrik (statistik inferensia). Cara yang di pakai oleh penulis dalam uji normalitas ini adalah Kolmogorov smirnov dengan bantuan program SPSS versi 23.00 .

Uji kolmogorov smirnov merupakan pengujian normalitas yang banyak dipakai, terutama setelah adanya banyak program statistik yang beredar. Kelebihan dari uji ini adalah sederhana dan tidak menimbulkan perbedaan persepsi di antara satu pengamat dengan pengamat yang lain jika signifikansi di atas 0,05 maka berarti tidak terdapat perbedaan yang signifikan antara data yang akan diuji dengan data normal baku, artinya data yang kita uji normal.

\section{Uji Analisa Korelasi Pearson Product Moment}

Uji analisa korelasi pearson product moment adalah jenis uji korelasi yang digunakan untuk mengetahui derajat keeratan hubungan 2 variabel.

Adapun Rumusnya :

$$
r=\frac{\sum(X-x)-(Y-y)}{\sqrt{\left[(X-x)^{2} \sqrt{[}\left[\sum y-y\right)^{2}\right\}}}
$$

Dimana:

$$
\begin{array}{ll}
X & =\text { Skor masing-masing item } \\
Y & =\text { Skor total } \\
X & =\text { Skor rata-rata variabel bebas } \\
y & =\text { Skor rata-rata variabel terikat }
\end{array}
$$

\section{Uji Analisa Deskriptif}

Kriteria keputusan dalam pengujian ini adalah dengan melihat nilai mean tertinggi pada pertanyaan-pertanyaan dalam setiap variabel yang ada. Pertanyaan yang memiliki nilai mean tertinggi akan mewakili setiap varibel sebagai faktor-faktor dominan menjadi penyebab keterlambatan proyek konstruksi gedung di kota Padang. 
Uji Analisa Deskritif menggunakan nilai rata-rata (Mean) dengan rumus sebagai berikut:

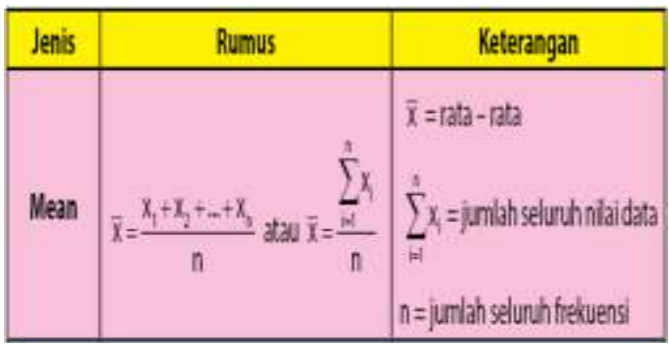

4. HASIL DAN PEMBAHASAN

a. Uji Validitas

Hasil Pengujian Validitas Variabel Pengaruh Bahan (X1)

\begin{tabular}{|c|c|c|c|c|}
\hline \multicolumn{5}{|c|}{ Uji Validitas Variabel Bahan (Material) } \\
\hline No & $\begin{array}{c}\text { Item } \\
\text { Pernyataan }\end{array}$ & $\begin{array}{c}\mathrm{r} \\
\text { Hitung }\end{array}$ & $\begin{array}{c}\mathrm{r} \\
\text { Tabel }\end{array}$ & Keterangan \\
\hline 1 & $\mathrm{X} 1-1$ & 0,427 & $\begin{array}{c}> \\
0,4227\end{array}$ & Item Valid \\
\hline 2 & $\mathrm{X} 1-2$ & 0,685 & $\begin{array}{c}> \\
0,4227\end{array}$ & Item Valid \\
\hline 3 & $\mathrm{X} 1-3$ & 0,712 & $\begin{array}{c}> \\
0,4227\end{array}$ & Item Valid \\
\hline 4 & $\mathrm{X} 1-4$ & 0,613 & $\begin{array}{c}> \\
0,4227\end{array}$ & Item Valid \\
\hline 5 & $\mathrm{X} 1-5$ & 0,842 & $\begin{array}{c}> \\
0,4227\end{array}$ & Item Valid \\
\hline 6 & $\mathrm{X} 1-6$ & 0,842 & $\begin{array}{c}> \\
0,4227\end{array}$ & Item Valid \\
\hline 7 & $\mathrm{X} 1-7$ & 0,790 & $\begin{array}{c}> \\
0,4227\end{array}$ & Item Valid \\
\hline 8 & $\mathrm{X} 1-8$ & 0,680 & $\begin{array}{c}> \\
0,4227\end{array}$ & Item Valid \\
\hline 9 & $\mathrm{X} 1-9$ & 0,472 & $\begin{array}{c}> \\
0,4227\end{array}$ & Item Valid \\
\hline 10 & $\mathrm{X} 1-10$ & 0,722 & $\begin{array}{c}> \\
0,4227\end{array}$ & Item Valid \\
\hline 11 & $\mathrm{X} 1-11$ & 0,757 & $\begin{array}{c}> \\
0,4227\end{array}$ & Item Valid \\
\hline 12 & $\mathrm{X} 1-12$ & 0,722 & $\begin{array}{c}> \\
0,4227\end{array}$ & Item Valid \\
\hline
\end{tabular}

Sumber : Data Primer 2018

Hasil Pengujian Validitas Variabel Pengaruh Tenaga Kerja (X2)

\begin{tabular}{|c|c|c|c|c|}
\hline \multicolumn{6}{|c|}{ Uji Validitas Variabel Tenaga kerja (Man Power) } \\
\hline No & $\begin{array}{c}\text { Item } \\
\text { Pernyataan }\end{array}$ & $\begin{array}{c}\mathrm{r} \\
\text { Hitung }\end{array}$ & $\begin{array}{c}\mathrm{r} \\
\text { Tabel }\end{array}$ & Keterangan \\
\hline 1 & $\mathrm{X} 2-1$ & 0,558 & $>$ & Item Valid \\
\hline
\end{tabular}

\begin{tabular}{|c|c|c|c|c|}
\hline 2 & $\mathrm{X} 2-2$ & 0,488 & $\begin{array}{c}\text { > } \\
0,4227\end{array}$ & Item Valid \\
\hline 3 & $\mathrm{X} 2-3$ & 0,617 & $\begin{array}{c}> \\
0,4227\end{array}$ & Item Valid \\
\hline 4 & $\mathrm{X} 2-4$ & 0,596 & $\begin{array}{c}> \\
0,4227\end{array}$ & Item Valid \\
\hline 5 & $\mathrm{X} 2-5$ & 0,641 & $\begin{array}{c}> \\
0,4227\end{array}$ & Item Valid \\
\hline 6 & $\mathrm{X} 2-6$ & 0,599 & $\begin{array}{c}> \\
0,4227\end{array}$ & Item Valid \\
\hline 7 & $\mathrm{X} 2-7$ & 0,663 & $\begin{array}{c}> \\
0,4227\end{array}$ & Item Valid \\
\hline 8 & $\mathrm{X} 2-8$ & 0,599 & $\begin{array}{c}> \\
0,4227\end{array}$ & Item Valid \\
\hline
\end{tabular}

Sumber : Data Primer 2018

Hasil Pengujian Validitas Variabel

Pengaruh Faktor Peralatan (X3)

\begin{tabular}{|c|c|c|c|c|}
\hline \multicolumn{5}{|c|}{ Uji Validitas Variabel faktor Peralatan } \\
(Equipment)
\end{tabular}

Sumber : Data Primer 2018

Hasil Pengujian Validitas Variabel

Pengaruh Keuangan (X4)

Uji Validitas Variabel Keuangan (Financing)

\begin{tabular}{|c|c|c|c|l|}
\hline No & $\begin{array}{c}\text { Item } \\
\text { Pernyataan }\end{array}$ & $\begin{array}{c}\mathrm{r} \\
\text { Hitung }\end{array}$ & $\begin{array}{c}\mathrm{r} \\
\text { Tabel }\end{array}$ & Keterangan \\
\hline 1 & $\mathrm{X} 4-1$ & 0,977 & $\begin{array}{c}> \\
0,4227\end{array}$ & Item Valid \\
\hline
\end{tabular}




\begin{tabular}{|c|c|c|c|c|}
\hline 2 & $\mathrm{X} 4-2$ & 0,570 & $\begin{array}{c}> \\
0,4227\end{array}$ & Item Valid \\
\hline 3 & $\mathrm{X} 4-3$ & 0,977 & $\begin{array}{c}> \\
0,4227\end{array}$ & Item Valid \\
\hline 4 & $\mathrm{X} 4-4$ & 0,815 & $\begin{array}{c}> \\
0,4227\end{array}$ & Item Valid \\
\hline
\end{tabular}

Sumber : Data Primer 2018

Hasil Pengujian Validitas Variabel

Pengaruh Lingkungan (X5)

\begin{tabular}{|c|c|c|c|c|}
\hline \multicolumn{5}{|c|}{ Uji Validitas Variabel Lingkungan (Environment) } \\
\hline & $\begin{array}{c}\text { Item } \\
\text { Pernyataa } \\
\mathrm{n}\end{array}$ & $\mathrm{r}$ Hitung & $\mathrm{r}$ Tabel & Keterangan \\
\hline 1 & $\mathrm{X} 5-1$ & 0,791 & $>0,4227$ & Item Valid \\
\hline 2 & $\mathrm{X} 5-2$ & 0,733 & $>0,4227$ & Item Valid \\
\hline 3 & $\mathrm{X} 5-3$ & 0,614 & $>0,4227$ & Item Valid \\
\hline 4 & $\mathrm{X} 5-4$ & 0,762 & $>0,4227$ & Item Valid \\
\hline 5 & $\mathrm{X} 5-5$ & 0,871 & $>0,4227$ & Item Valid \\
\hline
\end{tabular}

Hasil Pengujian Validitas Variabel Pengaruh

Perubahan (X6)

\begin{tabular}{|c|c|c|c|c|}
\hline \multicolumn{5}{|c|}{ Uji Validitas Variabel Perubahan (Change) } \\
\hline No & $\begin{array}{c}\text { Item } \\
\text { Pernyataan }\end{array}$ & $\begin{array}{c}\mathrm{r} \\
\text { Hitung }\end{array}$ & $\begin{array}{c}\mathrm{r} \\
\text { Tabel }\end{array}$ & Keterangan \\
\hline 1 & $\mathrm{X6-1}$ & 0,896 & $\begin{array}{c}> \\
0,4227\end{array}$ & Item Valid \\
\hline 2 & $\mathrm{X6-2}$ & 0,720 & $\begin{array}{c}> \\
0,4227\end{array}$ & Item Valid \\
\hline 3 & $\mathrm{X6-3}$ & 0,896 & $\begin{array}{c}> \\
0,4227\end{array}$ & Item Valid \\
\hline 4 & $\mathrm{X6-4}$ & 0,843 & $\begin{array}{c}> \\
0,4227\end{array}$ & Item Valid \\
\hline
\end{tabular}

Sumber : Data Primer 2018

Hasil Pengujian Validitas Variabel Pengaruh Kontrak (X7)

\begin{tabular}{|c|c|c|c|c|}
\hline \multicolumn{5}{|c|}{ Uji Validitas Variabel Kontrak (Contraktual } \\
Relationship) \\
\hline No & $\begin{array}{c}\text { Item } \\
\text { Pernyataan }\end{array}$ & $\begin{array}{c}\mathrm{r} \\
\text { Hitung }\end{array}$ & $\begin{array}{c}\mathrm{r} \\
\text { Tabel }\end{array}$ & Keterangan \\
\hline 1 & $\mathrm{X} 7-1$ & 0,940 & $\begin{array}{c}> \\
0,4227\end{array}$ & Item Valid \\
\hline 2 & $\mathrm{X} 7-2$ & 0,791 & $\begin{array}{c}> \\
0,4227\end{array}$ & Item Valid \\
\hline 3 & $\mathrm{X} 7-3$ & 0,791 & $\begin{array}{c}> \\
0,4227\end{array}$ & Item Valid \\
\hline 4 & $\mathrm{X} 7-4$ & 0,940 & $\begin{array}{c}> \\
0,4227\end{array}$ & Item Valid \\
\hline
\end{tabular}

Sumber : Data Primer 2018
Hasil Pengujian Validitas Variabel Pengaruh Keterlambatan Pada Konstruksi Gedung Terhadap Biaya (Y)

\begin{tabular}{|c|c|c|c|c|}
\hline \multicolumn{5}{|c|}{$\begin{array}{c}\text { Uji Validitas Variabel Pengaruh Keterlambatan } \\
\text { Proyek Gedung Terhadap biaya }\end{array}$} \\
\hline No & $\begin{array}{c}\text { Item } \\
\text { Pernyataan }\end{array}$ & $\begin{array}{c}\mathrm{r} \\
\text { Hitung }\end{array}$ & $\begin{array}{c}\text { r Tabel } \\
\text { Keterangan }\end{array}$ \\
\hline 1 & Y1-1 & 0,548 & $\begin{array}{c}> \\
0,4227\end{array}$ & Item Valid \\
\hline 2 & Y1-2 & 0,902 & $\begin{array}{c}> \\
0,4227\end{array}$ & Item Valid \\
\hline 3 & Y1-3 & 0,860 & $\begin{array}{c}> \\
0,4227\end{array}$ & Item Valid \\
\hline 4 & Y1-4 & 0,516 & $\begin{array}{c}> \\
0,4227\end{array}$ & Item Valid \\
\hline 5 & Y1-5 & 0,858 & $\begin{array}{c}> \\
0,4227\end{array}$ & Item Valid \\
\hline 6 & Y1-6 & 0,487 & $\begin{array}{c}> \\
0,4227\end{array}$ & Item Valid \\
\hline 7 & Y1-7 & 0,506 & $\begin{array}{c}> \\
0,4227\end{array}$ & Item Valid \\
\hline
\end{tabular}

Sumber : Data Primer 2018

\section{b. Uji Reliabilitas}

\section{Rekapitulasi Uji Reliabilitas}

\begin{tabular}{|c|c|c|c|}
\hline No & $\begin{array}{l}\text { Variabel Uji } \\
\text { Reliabilitas }\end{array}$ & $\begin{array}{l}\text { Cronback } \\
\text { alpa }\end{array}$ & Keterangan \\
\hline 1 & $\begin{array}{l}\text { BAHAN } \\
(\text { Material })(\mathrm{X} 1)\end{array}$ & 0,929 & Sempurna \\
\hline 2 & $\begin{array}{l}\text { TENAGA KERJA } \\
\text { (Man Power) (X2) }\end{array}$ & 0,848 & Tinggi \\
\hline 3 & $\begin{array}{l}\text { FAKTOR } \\
\text { PERALATAN } \\
\text { (Equipment) }(\mathrm{X} 3)\end{array}$ & 0,936 & Sempurna \\
\hline 4 & $\begin{array}{l}\text { KEUANGAN } \\
\text { (Financing) (X4) }\end{array}$ & 0,922 & Sempurna \\
\hline 5 & $\begin{array}{l}\text { LINGKUNGAN } \\
\text { (Environment) (X5) }\end{array}$ & 0,897 & Tinggi \\
\hline 6 & $\begin{array}{l}\text { PERUBAHAN } \\
\text { (Change) (X6) }\end{array}$ & 0,928 & Sempurna \\
\hline 7 & $\begin{array}{l}\text { KONTRAK } \\
\text { (contractual } \\
\text { relationship) }(\mathrm{X} 7)\end{array}$ & 0,873 & Tinggi \\
\hline 8 & $\begin{array}{l}\text { PENGARUH } \\
\text { FAKTOR } \\
\text { KETERLAMBATAN } \\
\text { PROYEK GEDUNG } \\
\text { TERHADAP } \\
\text { BIAYA(Y) }\end{array}$ & 0,880 & Tinggi \\
\hline
\end{tabular}

Sumber : Data Olahan SPSS 2018 
c. Uji Simirnov

\begin{tabular}{|c|c|c|c|}
\hline No & $\begin{array}{c}\text { Variabel Uji } \\
\text { Normalitas } \\
\text { Kolmogorov } \\
\text { Simirnov } \\
\end{array}$ & $\begin{array}{c}\text { Hasil } \\
\text { test }\end{array}$ & Keterangan \\
\hline 1 & $\begin{array}{l}\text { BAHAN } \\
(\text { Material })(\mathrm{X} 1)\end{array}$ & 0,360 & Normal \\
\hline 2 & $\begin{array}{l}\text { TENAGA KERJA } \\
\text { (Man Power) (X2) }\end{array}$ & 0,446 & Normal \\
\hline 3 & $\begin{array}{l}\text { FAKTOR } \\
\text { PERALATAN } \\
(\text { Equipment })(\mathrm{X} 3)\end{array}$ & 0,315 & Normal \\
\hline 4 & $\begin{array}{l}\text { KEUANGAN } \\
\text { (Financing) (X4) }\end{array}$ & 0,310 & Normal \\
\hline 5 & $\begin{array}{l}\text { LINGKUNGAN } \\
\text { (Environment) (X5) }\end{array}$ & 0,522 & Normal \\
\hline 6 & $\begin{array}{l}\text { PERUBAHAN } \\
\text { (Change) (X6) }\end{array}$ & 0,523 & Normal \\
\hline 7 & $\begin{array}{l}\text { KONTRAK } \\
(\text { contractual } \\
\text { relationship })(\mathrm{X} 7)\end{array}$ & 0,620 & Normal \\
\hline 8 & $\begin{array}{l}\text { PENGARUH } \\
\text { FAKTOR } \\
\text { KETERLAMBATAN } \\
\text { PROYEK GEDUNG } \\
\text { TERHADAP } \\
\text { BIAYA(Y) }\end{array}$ & 0,468 & Normal \\
\hline
\end{tabular}

\section{d. Analisa Korelasi Pearson Product}

\section{Moment}

Penyebab Faktor Kegagalan akibat keterlambatan proyek konstruksi Pada Bangunan Gedung Di Kota Padang yang Terkorelasi.

\begin{tabular}{|c|c|c|c|c|}
\hline \multirow[b]{2}{*}{ NO } & \multirow{2}{*}{$\begin{array}{c}\text { Penyebab } \\
\text { Faktor } \\
\text { kegagalan }\end{array}$} & \multicolumn{2}{|c|}{ Nilai Korelasi } & \multirow{2}{*}{$\begin{array}{c}\text { Hasil } \\
\text { Korelasi }\end{array}$} \\
\hline & & $\begin{array}{c}\text { Person } \\
\text { Correlation }\end{array}$ & Signifikan & \\
\hline 1 & $\begin{array}{l}\text { Jadwal } \\
\text { penggunaan } \\
\text { material (X1- } \\
11) \\
\end{array}$ & 0,609 & 0,003 & $\begin{array}{c}\text { Sangat } \\
\text { Kuat }\end{array}$ \\
\hline 2 & $\begin{array}{l}\text { Tempat } \\
\text { tinggal tenaga } \\
\text { kerja selama } \\
\text { pelaksanaan } \\
\text { proyek (X2-4) }\end{array}$ & 0,550 & 0,008 & $\begin{array}{c}\text { Sangat } \\
\text { Kuat }\end{array}$ \\
\hline 3 & $\begin{array}{l}\text { Informasi } \\
\text { ruang lingkup } \\
\text { pembagian } \\
\text { kerja yang } \\
\text { tidak detail } \\
\text { dan terencana }\end{array}$ & 0,481 & 0,024 & Kuat \\
\hline
\end{tabular}

\begin{tabular}{|c|c|c|c|c|}
\hline & (X2-5) & & & \\
\hline 4 & $\begin{array}{l}\text { Faktor sosial } \\
\text { dan budaya } \\
\text { (X5-1) }\end{array}$ & 0,457 & 0,032 & Kuat \\
\hline 5 & $\begin{array}{l}\text { Premanisme } \\
\text { (X5-2) }\end{array}$ & 0,439 & 0,041 & Kuat \\
\hline 6 & $\begin{array}{l}\text { Akses ke } \\
\text { lokasi proyek } \\
\text { sulit (X5-3) }\end{array}$ & 1,000 & 0,000 & $\begin{array}{c}\text { Sangat } \\
\text { Kuat }\end{array}$ \\
\hline 7 & $\begin{array}{l}\text { Pengaruh } \\
\text { udara dingin } \\
\text { pada saat } \\
\text { pelaksaan } \\
\text { konstruksi } \\
\text { (X5-5) }\end{array}$ & 0,831 & 0,000 & $\begin{array}{r}\text { Sangat } \\
\text { Kuat }\end{array}$ \\
\hline 8 & $\begin{array}{l}\text { Konflik antara } \\
\text { kontraktor dan } \\
\text { Konsultan } \\
(\mathrm{X} 7-1)\end{array}$ & 0,541 & 0,009 & $\begin{array}{c}\text { Sangat } \\
\text { Kuat }\end{array}$ \\
\hline 9 & $\begin{array}{l}\text { Kurangya } \\
\text { koordinasi } \\
\text { antara } \\
\text { kontraktor } \\
\text { engan owner } \\
\text { (X7-2) }\end{array}$ & 0,541 & 0,009 & $\begin{array}{c}\text { Sangat } \\
\text { Kuat }\end{array}$ \\
\hline 10 & $\begin{array}{l}\text { Keterlambatan } \\
\text { owner dalam } \\
\text { pengambilan } \\
\text { keputusan } \\
\text { (X7-3) }\end{array}$ & 0,541 & 0,009 & $\begin{array}{c}\text { Sangat } \\
\text { Kuat }\end{array}$ \\
\hline 11 & $\begin{array}{l}\text { Negosiasi dan } \\
\text { perijinan } \\
\text { dalam kontrak } \\
(\mathrm{X} 7-4)\end{array}$ & 0,541 & 0,009 & $\begin{array}{c}\text { Sangat } \\
\text { Kuat }\end{array}$ \\
\hline
\end{tabular}

Sumber : Data Olahan SPSS 2018 
Data yang sangat terkorelasi dengan nilai korelasi 1,000 dan signifikcant 0,000 .

\section{e. Analisa Deskriptif}

\begin{tabular}{|c|c|c|c|c|c|}
\hline \multirow[b]{2}{*}{$\begin{array}{l}\mathrm{N} \\
\mathrm{O}\end{array}$} & \multirow{2}{*}{$\begin{array}{c}\text { Faktor kegagalan } \\
\text { akibat keterlambatan } \\
\text { proyek konstruksi } \\
\text { pada bangunan } \\
\text { gedung di kota } \\
\text { Padang }\end{array}$} & & & \multirow[b]{2}{*}{$\begin{array}{c}\text { Mea } \\
n\end{array}$} & \multirow[b]{2}{*}{$\%$} \\
\hline & & $\begin{array}{l}\mathrm{M} \\
\mathrm{i} \\
\mathrm{n}\end{array}$ & $\begin{array}{l}\mathrm{M} \\
\mathrm{a} \\
\mathrm{x}\end{array}$ & & \\
\hline 1 & $\begin{array}{l}\text { Jadwal penggunaan } \\
\text { material yang } \\
\text { terperinci dan tepat } \\
\text { waktu (material's } \\
\text { schedule) }\end{array}$ & 2 & 4 & 3.50 & $\begin{array}{c}87,5 \\
\% \\
\end{array}$ \\
\hline 2 & $\begin{array}{l}\text { Tempat tinggal } \\
\text { tenaga kerja selama } \\
\text { pelaksanaan proyek }\end{array}$ & 3 & 4 & 3.36 & $84 \%$ \\
\hline 3 & $\begin{array}{l}\text {-Faktor sosial dan } \\
\text { budaya } \\
\text {-Akses ke lokasi } \\
\text { proyek sulit }\end{array}$ & 2 & 4 & 3.23 & $\begin{array}{c}80,75 \\
\%\end{array}$ \\
\hline 4 & 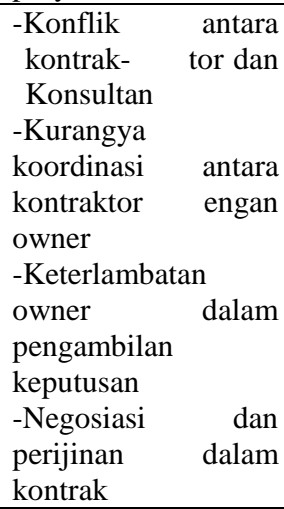 & 2 & 4 & 3.45 & $\begin{array}{c}86,25 \\
\%\end{array}$ \\
\hline
\end{tabular}

Sumber : Data Olahan SPSS 2018

Pengaruh yang paling dominan terhadap Faktor Kegagalan Akibat Keterlambatan Proyek Konstruksi Pada Bangunan Gedung Di Kota Padang

\begin{tabular}{|c|c|c|c|c|c|}
\hline \multirow[b]{2}{*}{$\begin{array}{l}\mathrm{N} \\
\mathrm{O}\end{array}$} & \multirow{2}{*}{$\begin{array}{c}\text { Pengaruh faktor } \\
\text { kegagalan akibat } \\
\text { keterlambatan proyek } \\
\text { gedung terhadap } \\
\text { biaya }\end{array}$} & & & \multirow[b]{2}{*}{$\begin{array}{l}\text { Me } \\
\text { an }\end{array}$} & \multirow[b]{2}{*}{$\%$} \\
\hline & & $\begin{array}{l}\mathrm{M} \\
\mathrm{i} \\
\mathrm{n}\end{array}$ & $\begin{array}{l}\mathrm{M} \\
\mathrm{a} \\
\mathrm{x}\end{array}$ & & \\
\hline 1 & $\begin{array}{l}\text { Penambahan biaya } \\
\text { tenaga kerja }\end{array}$ & 2 & 4 & $\begin{array}{c}3.6 \\
4\end{array}$ & $91 \%$ \\
\hline 2 & $\begin{array}{l}\text { Meningkatnya biaya } \\
\text { sewa peralatan } \\
\text { Konstruksi }\end{array}$ & 2 & 4 & $\begin{array}{c}3.5 \\
5\end{array}$ & $\begin{array}{c}88,75 \\
\%\end{array}$ \\
\hline 3 & $\begin{array}{l}\text { Biaya overhead } \\
\text { kantor menjadi lebih } \\
\text { Besar }\end{array}$ & 2 & 4 & $\begin{array}{c}3.5 \\
9\end{array}$ & $\begin{array}{c}89,75 \\
\%\end{array}$ \\
\hline 4 & $\begin{array}{l}\text { Biaya overhead } \\
\text { lapangan menjadi } \\
\text { lebih besar }\end{array}$ & 2 & 4 & $\begin{array}{c}3.4 \\
1\end{array}$ & $\begin{array}{c}85,25 \\
\%\end{array}$ \\
\hline
\end{tabular}

\begin{tabular}{|c|c|c|c|c|c|}
\hline 5 & $\begin{array}{l}\text { Penambahan biaya } \\
\text { perawatan dan } \\
\text { pemeliharaan selama } \\
\text { pelaksanaan }\end{array}$ & 2 & 4 & $\begin{array}{c}3.5 \\
0 \\
\end{array}$ & $\begin{array}{c}87,50 \\
\%\end{array}$ \\
\hline 6 & $\begin{array}{l}\text { Biaya penggantian } \\
\text { material dan } \\
\text { peralatan yang rusak }\end{array}$ & 2 & 4 & $\begin{array}{c}3.4 \\
5 \\
\end{array}$ & $\begin{array}{c}86,25 \\
\%\end{array}$ \\
\hline 7 & $\begin{array}{l}\text { Biaya akhir } \\
\text { pelaksanaan lebih } \\
\text { besardari biaya } \\
\text { rencana }\end{array}$ & 2 & 4 & $\begin{array}{l}3.5 \\
5\end{array}$ & $\begin{array}{l}88,75 \\
\%\end{array}$ \\
\hline
\end{tabular}

Sumber : Data Olahan SPSS 2018

\section{KESIMPULAN}

1. Berdasarkan penelitian yang telah dilakukan, maka penulis menyimpulkan hasil "Faktor Penyebab Kegagalan

Akibat Keterlambatan Proyek
Konstruksi Pada Bangunan Gedung Di

Kota Padang", adalah sebagai berikut:

Varibel dalam penelitian ini terdiri dari 7 variabel bebas yaitu variabel-variabel faktor penyebab kegagalan akibat keterlambatan pada proyek konstruksi gedung di kota padang sebagai variabel $X$ terdiri dari: Bahan (Material), Tenaga Kerja (man power), Faktor Peralatan (equipment), Keuangan (financing), Lingkungan (environment), Perubahan (change), Kontrak (contraktual relationship).

Adapun faktor penyebab kegagalan akibat keterlambatan pada proyek konstruksi gedung dikota padang yang ditinjau didapatkan 1 item dari Subfaktor yang menentukan sebagai penyebab keterlambatan penyelesaian proyek konstruksi gedung di kota Padang yaitu variabel bahan/material dengan nilai mean $3,50(87,50 \%)$ dan nilai signifikan 0,689 dengan signifikansi 0,003 $<0,05$ sesuai signifikansi yang disyaratkan.

1. Untuk melihat hubungan antara faktorfaktor penyebab keterlambatan 
penyelesaian proyek konstruksi gedung di kota Padang bagaimana pengaruhnya terhadap biaya, maka dilakukan pengujian analisa korelasi pearson product moment. Dari hasil pengujian yang dilakukan didapatkan nilai korelasi pada variabel Bahan (Material), Jadwal penggunaan material yang terperinci dan tepat waktu (material's schedule) adalah 0,609 dengan signifikansi $0,003<0,05$ signifikansi yang disyaratkan, variabel Tenaga Kerja (man power), Tempat tinggal tenaga kerja selama pelaksanaan proyek adalah 0,550 dengan signifikansi $0,008<0,05$ signifikansi yang disyaratkan, variabel Lingkungan (environment), Akses ke lokasi proyek sulit adalah 1 dengan signifikansi 0,000 $<0,05$ signifikansi yang disyaratkan, variabel Kontrak (contraktual relationship), Konflik antara kontraktor dan Konsultan, Kurangya koordinasi antara kontraktor engan owner, Keterlambatan owner dalam pengambilan keputusan, Negosiasi dan perijinan dalam kontrak adalah 0,541 dengan signifikansi $0,009<0,05$ signifikansi yang disyaratkan, dari semua variabel penyebab Faktor kegagalan akibat keterlambatan proyek konstruksi pada bangunan gedung di kota Padang dengan pengaruh faktor keterlambatan (kegagalan) proyek gedung terhadap biaya pada proyek konstruksi gedung yang paling signifikan ialah variabel Lingkungan (environment), Akses ke lokasi proyek sulit adalah 1 dengan signifikansi $0,000<0,05$ signifikansi yang disyaratkan,. Dengan itu menunjukkan bahwa ada hubungan yang positif dan negatif atau searah antara faktor-faktor tersebut terhadap bangunan konstruksi gedung di kota Padang. Hubungan positif dan searah yang dimaksud jika terjadi kenaikan terhadap faktor-faktor yang sudah didapatkan tersebut maka akan terjadi pula kenaikan terhadap biaya sebaliknya jika Hubungan negative dan tidak searah yang dimaksud jika terjadi kenaikan terhadap faktor-faktor yang sudah didapatkan tersebut maka tidak terjadi kenaikan terhadap biaya.

\section{DAFTAR PUSTAKA}

Aal, A.E. 1995. Cause of delay in large Building Construction Project, Teknik sipil. Journal Vol.5

Arifin, johar. 2017. 2017. SPSS 24 Untuk Penelitian dan Skripsi. Jakarta: Elex Media Komputindo

Assaf et al. 1995. Cause of delay in Large Building Construction Project, Journal of Management in Engginering, ASCE

Budiman Praboyo. 1999. Keterlambatan Waktu Pelaksanaan Dan Peringkat Dari Peyebab-Peyebabnya untuk proyek yang ada di wilayah Surabaya

Dictionary of Science and Engineering McGraww-Hill. Vol 3

Ervianto, W. I. 2005. Teori Aplikasi Manajemen Proyek Konstrksi Edisi Revisi. Yogyakarta: Penerbit Andi

Gray, C. F. 2006. Manajemen proyek, New York: Penerbit Andi

Hartono \& Lukman. 2013. Pengaruh Aspek Pelaksanaan Konstuksi Terhadap Kinerja Waktu Proyek. Jawa Tengah: ServiensinLumineVariatis

Hasan, lqbal. 2011. Pokok-Pokok Materi Statistik 1 (Statistik Deskriptif). Jakarta: Bumi Aksara

Haekal Hassan. 2016. Faktor-Faktor Penyebab Keterlambatan Pada Proyek Konstruksi Dan Alternatif Penyelesaiannya (Studi Kasus: Di Manado Town Square III)

Hasoloan Benget Sianipar. (2012). Analisis Faktor-Faktor Penyebab Keterlambatan Penyelesaian Proyek Konstruksi Pengaruhnya Terhadap Biaya Di 
Wilayah Karesidenan Surakarta.

I.A. Rai Widhiawati. (2009). Analisis FaktorFaktor Penyebab Keterlambatan Pelaksanaan Proyek Konstruksi untuk proyek- proyek yang ada di wilayah Bali.

Institut Teknologi Surabaya. (2011). Analisa Resiko Konstruksi Pada Proyek

Pudjosunarto Mulyadi Drs. 1991. Evaluasi Proyek. Yogyakarta: Penerbit Liberti.

Soeharto, Imam. 2003. Manajemen Proyek. Jakarta: Erlangga

Sugiyono. 2005. Metode Penelitian Administrasi. Bandung: Alfabeta

Suyatno. 2010. Analisis Faktor Penyebab Keterlambatan Peyelesaian Proyek Gedung (Aplikasi Model Regresi) untuk proyek yang ada di wilayah Surakarta.

Syofian Yamin, Heri Kurniawan. 2014. Teknik Analisis Statistik Terlengkap Dengan Sofware SPSS. Jakarta: Penrbit Salembah Imfotek. 